\title{
Contents / Inhalt
}

English Version

Notes on Use

A. Purpose, Scope, Informational Value $\ldots \ldots \ldots \ldots \ldots \ldots$ vii

B. Content of Entries . . . . . . . . . . . . . . . . . vii

C. Cross-references and Biographical Unity ............ vii

D. Orthography and Naming $\ldots \ldots \ldots \ldots \ldots \ldots \ldots \ldots$ vii

E. Arrangement $\ldots \ldots \ldots \ldots \ldots \ldots \ldots \ldots \ldots \ldots$ vii

F. Structure of Biographical Entries . . . . . . . . . . . . . viii

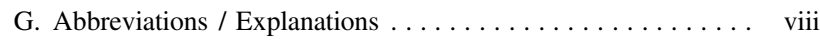

H. Conclusion .......................... viii

\section{Deutsche Version}

Hinweise für den Benutzer

A. Funktion und Informationswert $\ldots \ldots \ldots \ldots \ldots \ldots \ldots$ ix

B. Inhalt der Einträge $\ldots \ldots \ldots \ldots \ldots \ldots \ldots$ ix

C. Verweisungen und biographische Einheit ........... ix

D. Schreibweise und Namensansetzung $\ldots \ldots \ldots \ldots \ldots$ ix

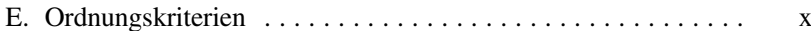

F. Struktur eines Eintrags im AIBI $\ldots \ldots \ldots \ldots \ldots \ldots \ldots \ldots$

G. Abkürzungen / Zeichenerklärung $\ldots \ldots \ldots \ldots \ldots \ldots \ldots$ x

H. Abschließende Bemerkung $\ldots \ldots \ldots \ldots \ldots \ldots \ldots \ldots \ldots$

List of Sources

Quellenverzeichnis

1. A - Ar

2. As - Isi

3. Isk - Nan

4. Nao - Z 
